\title{
SATUAN LINGUAL DAN SISTEM SAPAAN ISTILAH KEKERABATAN BAHASA BALI KASTA KSATRI DI JERO TENGAH KABUPATEN TABANAN
}

\author{
I Gusti Ayu Putu Istri Aryasuari \\ Pendidikan Bahasa Indonesia dan Daerah, \\ Fakultas Keguruan dan Ilmu Pendidikan, Universitas Dwijendra \\ istriaryasuari15@undwi.ac.id
}

\begin{abstract}
Abstrak
Penelitian ini meneliti satuan lingual sapaan istilah kekerabatan Bahasa Bali di kalangan kasta ksatria di Jero Tengah Kabupaten Tabanan. Penelitian ini khusus meneliti di satu keluarga besar Jero Tengah yang terletak di Banjar Tegal Baleran Kabupaten Tabanan. Penelitian ini bertujuan untuk mengetahui satuan lingual sapaan istilah kekerabatan Bahasa Bali kasta ksatria di Jero Tengah. Kasta Ksatria yang diteliti yaitu yang menggunakan nama Gusti. Metode pengumpulan data yang dilakukan dengan metode wawancara dengan narasumber dan dilanjutkan dengan teknik catat. Metode analisis data digunakan dengan metode agih, yaitu metode yang alat penentunya itu justru bagian dari Bahasa yang bersangkutan itu sendiri. Metode penyajian hasil analisis data menggunakan metode informal, yaitu hasil analisis disajikan dengan kata-kata dan kalimat. Satuan-satuan lingual sapaan istilah kekerabatan Bahasa Bali kasta ksatria di Jero Tengah yang ditemukan yaitu, kompyang 'buyut', ninik, mbah 'nenek', wayah 'kakek', ajik 'ayah', biang 'ibu', utik 'ibu', 'ibu', ji + urutan kelahiran 'paman', biang + urutan kelahiraan 'bibi', tik + urutan kelahiran 'bibi', bu + urutan kelahiran 'bibi', titu 'bibi', raka + urutan kelahiran 'kakak laki-laki', wi gus 'kakak laki-laki', mbok gek 'kakak perempuan', gung + nama, gung + urutan kelahiran / nama saja 'adik laki-laki/perempuan'. Satuan lingual dan sistem sapaan istilah kekerabatan Bahasa Bali yang ditemukan beragam sesuai dengan penggunaannya.
\end{abstract}

Kata kunci: satuan lingual, sapaan istilah kekerabatan, bahasa Bali, kasta ksatria

\begin{abstract}
This research examined the lingual units of greeting of Balinese kinship terms among ksatria caste in Jero Tengah Tabanan Regency. This study specifically examined a large family of Jero Tengah located in Banjar Tegal Baleran, Tabanan Regency. This study aimed to determine the lingual units of greeting of Balinese kinship terms among ksatria caste in Jero Tengah. The Ksatria caste studied were those whose names were Gusti. The data collection method was carried out by interviewing the interviewees and continued with note taking. The data analysis method used was the distribution method that is the method in which the determinant is precisely the part of the language itself. The method of presenting the results of the data analysis was informal method, in which the results of the analysis were presented by using words and sentences. The lingual units of greeting of Balinese kinship terms among ksatria caste in Jero Tengah found were kompyang 'great-grandfather', ninik, mbah 'grandmother', wayah 'grandfather', ajik 'father', biang 'mother', utik 'mother', $j i+$ birth order 'uncle', biang + birth order 'aunt', tik + birth order 'aunt', $b u$ + birth order 'aunt', titu 'aunt', raka + birth order 'older brother ', wi gus 'older brother', mbok gek 'older sister', gung + name, gung + birth order / name only 'younger brother / sister'. Lingual units and greeting systems of Balinese kinship terms found were various according to their use.
\end{abstract}

Keywords: lingual units, greeting of kinship terms, Balinese, Ksatria caste

\section{PENDAHULUAN}

Bahasa Bali merupakan Bahasa ibu bagi masyarakat Bali. Bahasa Bali merupakan salah satu Bahasa yang unik, karena Bahasa Bali memiliki sistem tingkatan kesopanan kebahasaan. Tingkat kesopanan Bahasa Bali berpengaruh terhadap sistem wangsa. Menurut Suwendi (2014) dalam tataran wangsa, membedakan masyarakat daerah Bali ke dalam klan brahmana; ksatria, dan wesia (tri wangsa) dan klan jaba atau sudra (catur wangsa). Sementara itu, dari sudut warna (profesi), pemakaian bahasa Bali yang 
bertingkat- tingkat juga telah mengalami perubahan, yakni lebih melihat kedudukan masyarakat dalam fungsi-fungsi sosial di masyarakatnya.

Namun, di Bali mulai mengalami pergeseran wangsa menjadi kasta. Sistem kasta di Bali merupakan sistem yang diwariskan oleh Belanda ketika masa penjajahan Belanda. Kasta dalam Dictionary of American English disebut : "Caste is a group resulting from the division of society based on class, difference of wealth, rank, rights, profession, or job." Uraian lebih luas ditemukan pada Encyclopedia Americana Volume 5 halaman 775; asal katanya adalah "Casta” Bahasa Portugis yang berarti kelas, ras keturunan, golongan, pemisah, tembok atau batas.

Kasta di Bali dibagi menjadi empat golongan yaitu brahmana, kesatria, waisya dan sudra. Wiana (2006: 10) menyebut keempat golongan tersebut dengan sebutan catur wangsa, catur warna atau kasta. Brahmana merupakan golongan sosial yang paling tinggi, karena merupakan keturunan pemuka agama dan memimpin setiap acara keagamaan. Kasta kesatria merupakan golongan tertinggi kedua setelah brahmana. Golongan kesatria merupakan para keturunan raja, bangsawan, dan pejabat pada jaman dahulu. Nama keturunan kesatria ditandai dengan Anak Agung, Cokorda, Gusti, Dewa, Dewa Ayu, Desak dan Sagung. Penamaan dengan awalan Dewa Ayu, Desak dan Sagung hanya digunakan oleh perempuan. Golongan waisya merupakan golongan keturunan pengusaha, pedagang dan juragan pada jaman kerajaan. Golongan sudra tidak memiliki gelar khusus sehingga memilih pemberian nama berdasarkan urutan kelahiran pada umumnya (Budi, 2012). Secara garis besar menurut "Sastra Kanda Pat Sari” dalam Budi (2012), terdapat empat macam penamaan berdasarkan urutan kelahiran masing-masing dari yang tertua sampai termuda, yaitu Wayan atau Putu atau Gede, Made atau Kadek, Nyoman atau Komang, dan Ketut. Penelitian Adnyana, Suar (2018) yang berjudul "Variasi Linguistik Bahasa Tetun Dialek Fehan: Sebuah Kajian Awal", menyatakan bahwa masyarakat Fehan memiliki sistem nama diri berdasarkan urutan kelahiran (2018: 95), sama halnya dengan nama orang Bali, namun orang Bali menggunakan nama tersebut sebagai penanda urutan kelahiran.

Sapaan istilah kekerabatan Bahasa Bali dipengaruhi oleh sistem kasta. Kridalaksana (1982) mengatakan bahwa yang termasuk katakata sapaan dalam bahasa Bali dapat berbentuk morfem, kata-kata, dan atau frasa. Bentuk katakata sapaan tersebut digunakan untuk saling merujuk dalam situasi pembicaraan yang berbeda-beda menurut sifat hubungan antara pembicara itu. Pada penelitian ini meneliti sapaan istilah kekerabatan Bahasa Bali kasta ksatria di Jero Tengah Tabanan. Keluarga Jero Tengah yang diteliti menggunakan gelar Gusti pada namanya. Penelitian ini dilakukan untuk mengetahui variasi satuan lingual sapaan istilah-istilah kekerabatan kasta Ksatria yang menggunakan gelar nama Gusti.

\section{METODE PENELITIAN}


Metode penelitian yang digunakan dalam penelitian ini dibagi menjadi metode penelitian dan teknik pengumpulan data, metode dan teknik analisis data, serta metode dan teknik hasil analisis data. Metode yang digunakan untuk mengumpulkan data adalah metode wawancara dengan teknik lanjutan teknik catat (Sudaryanto, 1993: 92). Metode wawancara digunakan untuk mewawancarai narasumber untuk memperoleh sapaan istilah-istilah kekerabatan di golongan kasta ksatria, kemudian dilanjutkan dengan mencatat istilahistilah kekerabatan yang diteliti. Istilah-istilah kekerabatan tersebut kemudian diklasifikasikan sesuai dengan fungsinya dan perbedaan penggunaannya. Metode analisis data menggunakan metode agih dengan teknik lanjutan bagi unsur langsung (Sudaryanto, 1993: 36). Metode agih menggunakan alat penentu dasar Bahasa yang diteliti. Dasar penentu di dalam kerja metode agih adalah teknik pemilihan data berdasarkan kategori (kriteria) tertentu dari segi kegramatikalan sesuai dengan ciri-ciri alami yang dimiliki oleh data penelitian (Sudaryanto, 1993: 30). Alat penentu dalam rangka kerja metode agih selalu berupa bagian atau unsur dari Bahasa objek sasaran penelitia itu sendiri, istilah-istilah kekerabatan kasta ksatria, yang dilanjutkan dengan teknik lanjutan bagi unsur langsung yaitu, dengan membagi unsur-unsur istilahistilah kekerabatan. Metode dan teknik penyajian hasil analisis data menggunakan metode informal. Sudaryanto (1993: 144) menyatakan metode penyajian hasil analisis data informal merupakan merupakan penyajian hasil analisis data dengan menggunakan karakata atau penjelasan.

\section{PEMBAHASAN}

3.1 Satuan Lingual Istilah-istilah

Kekerabatan Sapaan Bahasa Bali dan

\section{Variasinya}

Setelah dilakukan wawancara dengan

narasumber, ditemukan istilah-istilah kekerabatan untuk menyebut buyut, kakek, nenek, ayah, ibu, paman, bibi, kakak laki-laki, kakak perempuan, adik laki-laki dan adik perempuan beserta variasinya. Tabel berikut menunjukkan data-data yang diperoleh dari hasil penelitian.

Tabel 1 Satuan Lingual Istilah Kekerabatan Sapaan Bahasa Bali dan Variasinya sebagai berikut.

\begin{tabular}{|l|l|}
\hline Istilah & Satuan Lingual \\
Kekerabatan & Istilah \\
& Kekerabatan \\
& Sapaan Bahasa \\
& Bali dan \\
& Variasinya \\
\hline Buyut & kompyang \\
\hline Kakek & wayah \\
\hline Nenek & - ninik \\
& - mbah \\
\hline Ayah & - aji \\
& - ajik \\
\hline Ibu & - biang \\
& - utik \\
& - ibu \\
\hline Paman & - aji tu \\
& - aji ade \\
& - aji mang \\
& - aji tut \\
\hline
\end{tabular}




\begin{tabular}{|c|c|}
\hline & $\begin{array}{l}-\quad \text { ji tu } \\
\text { - ji ade } \\
\text { - ji mang } \\
\text { - ji tut } \\
\text { - } \text { pak mang }\end{array}$ \\
\hline Bibi & $\begin{array}{l}\text { - biang tu } \\
\text { - biang ade } \\
\text { - tik de } \\
\text { - ti tu } \\
\text { - bu tu } \\
\text { - bu ngah }\end{array}$ \\
\hline $\begin{array}{l}\text { Kakak laki- } \\
\text { laki }\end{array}$ & $\begin{array}{l}\text { - } \text { raka tu } \\
\text { - raka de } \\
\text { - raka mang } \\
\text { - wi gus } \\
\text { - wi gus bayu } \\
\text { - wi darma }\end{array}$ \\
\hline $\begin{array}{l}\text { Kakak } \\
\text { perempuan }\end{array}$ & $\begin{array}{l}\text { - mbok gek } \\
\text { - mbok erna } \\
\text { - mbok anik }\end{array}$ \\
\hline Adik laki-laki & $\begin{array}{l}\text { - gung wahyu } \\
\text { - gung rai } \\
\text { - gung tu } \\
\text { - gung mang } \\
\text { - rai }\end{array}$ \\
\hline $\begin{array}{l}\text { Adik } \\
\text { perempuan }\end{array}$ & $\begin{array}{l}\text { - gung novi } \\
\text { - gung tu } \\
\text { - gung istri } \\
\text { - malika }\end{array}$ \\
\hline
\end{tabular}

\subsection{Penggunaan Satuan Lingual Sapaan} Istilah-Istilah Kekerabatan Sapaan Bahasa Bali dan Variasinya

Satuan lingual sapaan istilah kekerabatan sapaan Bahasa Bali dan variasi yang diperolah memiliki fungsi dan penggunaannya masingmasing. Satuan lingual kompyang 'buyut' merupakan sapaan yang digunakan untuk menyebut atau menyapa buyut, dan memiliki variasi kompyang lanang untuk menyebut buyut laki-laki serta kompyang istri untuk menyebut buyut perempuan. Variasi sapaan untuk menyapa buyut lainnya yaitu, pyang yang merupakan pemotongan kata dari kata kompyang.

Satuan lingual untuk menyebut kakek dalam sapaan Bahasa Bali yaitu wayah. Wayah digunakan untuk menyebut dan menyapa kakek yang berkasta. Variasi sapaan untuk menyapa kakek yaitu, wayah dan yah. Satuan lingual untuk menyebut dan menyapa nenek yaitu ninik dan mbah. Variasi sapaan untuk menyapa nenek yaitu ninik, nik dan mbah. Ninik dan nik biasanya digunakan untuk menyapa nenek yang berkasta, sedangkan mbah biasanya digunakan untuk menyapa nenek yang berasal dari keluarga tidak berkasta dan masuk ke keluarga ksatria.

Aji dan ajik merupakan satuan lingual untuk menyebut dan menyapa ayah. Sapaan aji memiliki tingkat kesopanan lebih tinggi dibandingan dengan ajik. Satuan lingual untuk menyebut dan menyapa ibu yaitu biang, utik, dan ibu. Biang dan utik digunakan untuk menyapa dan menyebut ibu yang berkasta atau berkasta ksatria, sedangkan $i b u$ digunakan untuk menyebut ibu yang berasal dari keluarga tidak berkasta dan menikah dengan keluarga berkasta ksatria.

Satuan lingual untuk menyebut dan menyapa paman yang ditemukan yaitu, aji tu, aji ade, aji tut, ji tu, ji ade, ji tut dan pak mang. Aji tu, aji ade, aji tut, ji tu, ji ade, ji tut merupakan sapaan untuk menyebut dan 
menyapa paman yang berasal dari keluarga yang berkasta atau satu keturunan dengan kakek, sedangkan pak mang merupakan sapaan untuk menyebut dan menyapa paman yang tidak berkasta. Aji tu atau ji tu merupakan sapaan yang berasal dari kata ajik putu, dimana putu merupakan nama yang menunjukkan urutan kelahiran anak pertama, sama halnya dengan aji ade atau ji ade yang berasal dari ajik made atau paman yang merupakan anak kedua. Aji mang atau ji mang berasal dari kata ajik dan komang, komang merupakan nama urutan kelahiran anak ketiga sehingga aji manga atau ji mang merupakan ayah yang lahir ketiga , sedangkan aji tut atau ji tut yang berasal dari kata aji ketut yang artinya ayah yang lahir keempat. Pak mang merupakan sapaan yang berasal dari kata bapak dan komang, dimana komang merupakan penanda urutan kelahiran anak ketiga sehingga menjadi bapak ketiga untuk menyebut paman yang tidak berkasta. Variasi untuk menyebut paman ada dua yaitu, aji / ji + urutan kelahiran dan $p a k+$ urutan kelahiran.

Biang tu, biang de, tik de, ti tu, bu tu dan bu ngah merupakan satuan lingual untuk menyebut dan menyapa bibi di kalangan jero tengah. Biang tu merupakan sapaan yang berasal dari kata biang dan putu yang artinya ibu anak pertama, sedangkan biang de merupakan sapaan yang berasal dari kata biang dan made yang artinya bibi anak kedua. Tik de berasal dari kata utik dan made yang artinya ibu anak kedua, sedangkan $t i$ tu berasal dari kata $i b u$ dan putu yang artinya ibu anak pertama. Biang tu, biang de, tik de dan ti tu digunakan untuk menyapa bibi yang berasal dari keluarga yang berkasta. $B u$ tu berasal dari kata $i b u$ dan putu yang artinya ibu anak pertama, sedangkan bu ngah berasal dari kata $i b u$ dan nengah yang artinya ibu anak kedua. Bu tu dan bu ngah digunakan untuk menyapa dan menyebut bibi yang berasal dari keluarga yang tidak berkasta dan menikah dengan keluarga berkasta.

Satuan lingual untuk menyebut dan menyapa kakak laki-laki yaitu, raka tu, raka de, raka mang, wi gus, wi gus bayu dan wi darma. Raka tu berasal dari kata raka 'kakak' dan putu 'anak pertama', sehingga raka tu berarti kakak laki-laki pertama. Raka de berasal dari kata raka dan made yang artinya kakak laki-laki kedua, sama halnya dengan raka mang yang berasal dari raka dan komang yang artinya kakak laki-laki ketiga, sehingga variasi penggunaan sapaan raka dapat disimpulakan dengan raka + urutan kelahiran. Wi memiliki arti kakak laki-laki, dan gus berasal dari kata bagus. Variasi penggunaan wi gus yang ditemukan yaitu, wi gus bayu, dimana bayu merupakan nama diri, dan wi darma, dimana darma merupakan nama diri, sehingga variasi yang dibentuk yaitu, wi gus + nama diri dan $w i+$ nama diri. Satuan lingual yang digunakan untuk menyebut dan menyapa kakak perempuan yang ditemukan yaitu, mbok gek, mbok gek erna dan mbok gek anik. Mbok gek sendiri memiliki arti kakak perempuan, sehingga untuk variasi mbok gek erna dan mbok gek anik, merupakan pembentukan dari mbok gek ditambah dengan nama diri.

Gung wahyu, gung rai, gung tu, gung mang dan rai merupakan variasi satuan lingual istilah kekerabatan yang digunakan untuk 
menyapa dan menyebut adik laki-laki. Gung merupakan sapaan yang sering digunakan untuk menyapa seseorang yang berkasta ksatria di Jero Tengah Tabanan. Gung dapat digunakan untuk menyapa laki-laki perempuan. Gung wahyu dan gung rai merupakan sapaan gung ditambah dengan nama diri. Gung tu berasal dari kata gung dan putu yang artinya adik laki-laki pertama, sedangkan gung mang merupakan sapaan untuk menyapa adik laki-laki ketiga, dimana mang berasal dari kata komang yang merupakan penanda urutan kelahiran anak ketiga. Variasi sapaan yang ditemukan terakhir untuk menyapa adik laki-laki yaitu nama diri. Satuan lingual untuk menyapa dan menyebut adik perempuan yang ditemukan yaitu, gung novi, gung tu, gung istri dan malika. Seperti yang telah dijelaskan sebelumnya, gung merupakan sapaan yang dapat digunakan untuk menyapa laki-laki dan perempuan. Gung novi dan gung Istri merupakan variasi sapaan yang berasal dari sapaan gung + nama diri. Gung tu merupakan sapaan yang berasal dari sapaan gung + putu yang merupakan penanda urutan kelahiran anak perempuan. Variasi sapaan untuk menyapa adik perempuan yaitu, gung + nama diri, gung + urutan kelahiran dan nama diri.

\subsection{Sistem Sapaan Istilah-Istilah}

\section{Kekerabatan dan Variasinya}

Data-data satuan lingual sapaan istilah kekerabatan yang telah dianalisis kemudian, disistematikakan sehingga menghasilkan sistem sapaan istilah-istilah kekerabatan dan variasinya sebagai berikut
Tabel 2 Sistem Sapaan Istilah-Istilah Kekerabatan

\begin{tabular}{|c|c|}
\hline $\begin{array}{l}\text { Istilah } \\
\text { Kekerabatan }\end{array}$ & $\begin{array}{l}\text { Istilah Kekerabatan } \\
\text { Sapaan Bahasa Bali } \\
\text { dan Variasinya }\end{array}$ \\
\hline Buyut & Kompyang \\
\hline Kakek & Wayah \\
\hline Nenek & $\begin{array}{l}\text { - ninik } \\
\text { - mbah }\end{array}$ \\
\hline Ayah & $\begin{array}{l}-\quad \text { aji } \\
\text { - } \quad \text { ajik }\end{array}$ \\
\hline Ibu & $\begin{array}{l}\text { - } \quad \text { biang } \\
\text { - } \quad \text { utik } \\
\text { - } \quad i b u\end{array}$ \\
\hline Paman & $\begin{array}{l}\text { - } j i+\text { urutan kelahiran } \\
\text { - } \text { pak+urutan } \\
\text { kelahiran }\end{array}$ \\
\hline Bibi & $\begin{array}{l}\text { - biang+urutan } \\
\text { kelahiran } \\
\text { - tik+urutan kelahiran } \\
\text { - bu+urutan } \\
\text { kelahiran }\end{array}$ \\
\hline $\begin{array}{l}\text { Kakak laki- } \\
\text { laki }\end{array}$ & $\begin{array}{l}\text { - } \text { raka+urutan } \\
\text { kelahiran } \\
\text { - wi gus } \\
\text { - wi gus + nama diri } \\
\text { - wi+nama diri }\end{array}$ \\
\hline $\begin{array}{l}\text { Kakak } \\
\text { perempuan }\end{array}$ & $\begin{array}{l}\text { - mbok gek } \\
\text { - mbok+nama diri }\end{array}$ \\
\hline $\begin{array}{l}\text { Adik laki- } \\
\text { laki }\end{array}$ & $\begin{array}{l}\text { - gung+nama diri } \\
\text { - gung+urutan } \\
\text { kelahiran } \\
\text { - nama diri }\end{array}$ \\
\hline $\begin{array}{l}\text { Adik } \\
\text { perempuan }\end{array}$ & $\begin{array}{l}\text { - gung+nama diri } \\
\text { - gung+urutan } \\
\text { kelahiran }\end{array}$ \\
\hline
\end{tabular}


Dari tabel tersebut kita dapat melihat bagaimana sistem dan terbentuknya satuan lingual sapaan Bahasa Bali istilah-istilah kekerabatan dan variasinya di Keluarga Ksatria yang ditemukan di keluarga Jero Tengah, Tabanan.

\section{PENUTUP}

Dari data-data yang diperoleh dan dianalisis dapat disimpulkan bahwa satuan lingual sapaan istilah kekerabatan Bahasa Bali Kasta Ksatria di Jero Tengah Kabupaten Tabanan, yaitu kompyang 'buyut', wayah 'kakek', ninik dan mbah 'nenek', aji dan ajik 'ayah', biang, utik dan ibu 'ibu', aji tu, aji ade, aji mang, aji tut, ji tu, ji ade, ji mang, ji tut dan pak mang 'paman, biang tu, biang ade, tik de, ti tu, bu tu, dan bu ngah 'bibi', raka tu, raka de, raka mang, wi gus, wi gus bayu, dan wi darma 'kakak laki-laki', mbok gek, mbok erna, dan mbok gek anik 'kakak perempuan', gung wahyu, gung rai, gung tu, gung mang dan rai 'adik laki-laki', gung novi, gung tu, gung istri dan malika 'adik perempuan'.

Sistem sapaan istilah-istilah kekerabatan yang dapat disimpulkan yaitu, kompyang 'buyut', wayah 'kakek', ninik dan mbah 'nenek', aji dan ajik 'ayah', biang, utik, ibu 'ibu', ji+urutan kelahiran 'paman', pak+urutan kelahiran 'paman'. Biang+urutan kelahiran 'bibi', tik+urutan kelahiran 'bibi', $b u+$ urutan kelahiran 'bibi. Raka+urutan kelahiran 'kakak laki-laki', wi gus + nama diri 'kakak laki-laki', mbok gek 'kakak perempuan', mbok+nama diri 'kakak perempuan', gung+nama diri 'adik laki-laki atau adik perempuan', gung+urutan kelahiran 'adik laki-laki atau adik perempuan', nama diri dapat digunakan untuk menyapa dan menyebut adik laki-laki atau adik perempuan.

\section{DAFTAR PUSTKA}

Adnyana, Suar. 2018. Variasi Linguistik Bahasa Tetun Dialek Fehan: Sebuah Kajian Awal. Linguistik Indonesia: Masyarakat Linguistik Indonesia.

Budi. 2012. Budaya Bali: Nama Orang Bali [Posting Laman]. Diambil dari http://cakepane.blogspot.co.id/2012/0 7/nama-orang-bali.html pada tanggal 3 Maret 2020.

Kridalaksana, Harimurti. 1982. Kamus Linguistik Indonesia. Jakarta: Gramedia

Sudaryanto. 1993. Metode dan Aneka Teknik Analisis Bahasa (Pengantar Penelitian Wahana Kebudayaan Secara Linguistis). Yogyakarta: Duta Wacana University Press.

Suwendi, I Made. 2014. Menuju Bahasa Bali yang Humanis (Reintersprestasi SorSinggih Bahasa Bali). Widyasrama: Majalah Ilmiah Universitas Dwijendra Denpasar.

Wiana, IK. 2006. Memahami Perbedaan Catur Warna, Kasta, dan Wangsa. Surabaya: Penerbit Paramita 